\title{
Kojic acid repurposing as a pancreatic lipase inhibitor and the optimization of its production from a local Aspergillus oryzae soil isolate
}

Sarah Mohamed El-Korany ${ }^{1}$, Omneya Mohamed Helmy ${ }^{1 *}$, Ali Mahmoud El-Halawany², Yasser El-Mohammadi Ragab ${ }^{1}$ and Hamdallah Hafez Zedan ${ }^{1}$

\begin{abstract}
Background: Obesity and its related diseases are increasing worldwide. One of the best therapeutic strategies for obesity management is through the inhibition of pancreatic lipase (PL) enzyme. So far orlistat is the only FDA approved PL inhibitor, but with unpleasant side effects. New efficacious anti-obesity drugs are needed to achieve a successful reduction in the incidence and prevalence of obesity. Many microbial metabolites have PL inhibitory activity. Screening soil inhabitants for PL inhibitors could help in increasing the available anti-obesity drugs. We aimed to isolate and identify alternative PL inhibitors from soil flora.

Results: We screened the crude mycelial methanolic extracts of 39 soil samples for PL inhibitory activity by the quantitative lipase colorimetric assay, using the substrate $p$-nitrophenyl palmitate and orlistat as positive control. AspsarO, a PL inhibitor producer, was isolated from an agricultural field soil in Giza, Egypt. It was identified as Aspergillus oryzae using colony morphology, microscopical characteristics, 185 rDNA sequencing, and molecular phylogeny. Increasing the PL inhibitor activity, in AspsarO cultures, from $25.9 \pm 2 \%$ to $61.4 \pm 1.8 \%$ was achieved by optimizing the fermentation process using a Placket-Burman design. The dried 100\% methanolic fraction of the AspsarO culture had an $I_{50}$ of $7.48 \mu \mathrm{g} / \mathrm{ml}$ compared to $3.72 \mu \mathrm{g} / \mathrm{ml}$ for orlistat. It decreased the percent weight gain, significantly reduced the food intake and serum triglycerides levels in high-fat diet-fed Sprague-Dawley rats. Kojic acid, the active metabolite, was identified using several biological guided chromatographic and ${ }^{1} \mathrm{H}$ and ${ }^{13} \mathrm{C}$ NMR techniques and had an $\mathrm{IC}_{50}$ of $6.62 \mathrm{\mu g} / \mathrm{ml}$. Docking pattern attributed this effect to the interaction of kojic acid with the key amino acids (Lys80, Trp252, and Asn84) in PL enzyme binding site.

Conclusion: Combining the results of the induced obesity animal model, in silico molecular docking and the lipase inhibitory assay, suggests that kojic acid can be a new therapeutic option for obesity management. Besides, it can lower serum triglycerides in obese patients.
\end{abstract}

Keywords: Anti-obesity, Pancreatic lipase inhibitor, Soil fungi, Aspergillus oryzae, Kojic acid, Orlistat, Anti-triglyceride

\footnotetext{
* Correspondence: omnia.helmy@pharma.cu.edu.eg

'Department of Microbiology and Immunology, Faculty of Pharmacy, Cairo University, Cairo, Egypt

Full list of author information is available at the end of the article
}

\section{$\triangle B M C$}

(c) The Author(s). 2020 Open Access This article is licensed under a Creative Commons Attribution 4.0 International License, which permits use, sharing, adaptation, distribution and reproduction in any medium or format, as long as you give appropriate credit to the original author(s) and the source, provide a link to the Creative Commons licence, and indicate if changes were made. The images or other third party material in this article are included in the article's Creative Commons licence, unless indicated otherwise in a credit line to the material. If material is not included in the article's Creative Commons licence and your intended use is not permitted by statutory regulation or exceeds the permitted use, you will need to obtain permission directly from the copyright holder. To view a copy of this licence, visit http://creativecommons.org/licenses/by/4.0/ The Creative Commons Public Domain Dedication waiver (http://creativecommons.org/publicdomain/zero/1.0/) applies to the data made available in this article, unless otherwise stated in a credit line to the data. 


\section{Background}

Obesity, a metabolic disorder characterized by the accumulation of lipids, poses a risk to human health [1]. It is associated with serious health conditions like insulin resistance, diabetes mellitus, cardiovascular diseases, and certain types of cancer, including endometrial, breast, ovarian, prostate, liver, gallbladder, kidney, and colon cancer [2, 3]. The World Health Organization (WHO) reported that 2.8 million people die annually because of obesity-related diseases [4]. There are more than 1.5 billion overweight adults worldwide, and this number is expected to rise to 3.3 billion by 2030 [5]. Among the 20 most populous countries, the highest level of adult obesity (35.3\%) was recorded in Egypt in 2015 [6].

Pancreatic lipase (PL) is the key enzyme in lipid metabolism. Its inhibition alters the absorption of the ingested triglycerides and is thus considered one of the major targets in obesity management [7]. Orlistat is the only FDA approved PL inhibitor for obesity treatment [8]; it is a saturated derivative of lipstatin, a potential natural PL inhibitor, isolated from the actinobacterium Streptomyces toxytricini [9]. However, it has many side effects including oily stools, flatulence, fecal urgency, and abdominal cramps [10]. Hepatotoxicity, the formation of gall and kidney stones, and acute pancreatitis are severe adverse effects occurring due to the long-term administration of orlistat [8]. These side effects have motivated researchers to explore new alternative sources for pancreatic lipase inhibitors, such as plants, bacterial, fungal, and marine species [7, 8, 11, 12], or synthesize completely synthetic PL inhibitors. Cetilistat (ATL-962) is a new synthetic PL inhibitor that had completed phase III clinical trials but is not yet approved [13].

Fungi are considered microbial cell factories that can produce various bioactive agents, including antitumor, antibacterial, antifungal, antiviral, and enzyme inhibitor compounds [14]. Aspergilli are ubiquitous filamentous fungi, known to secrete antibiotics, mycotoxins, immunesuppressants, and cholesterol-lowering agents [15-17]. Kojic acid (5-hydroxy-2-hydroxymethylgamma-pyrone, KA) is a major secondary metabolite of Aspergillus oryzae, Aspergillus flavus, Aspergillus tamarii, and Penicillium species $[18,19]$. Because of its biocompatibility, kojic acid has many medical applications. These include antimicrobial, antiviral, antitumor, antidiabetic, anticancer, antiparasitic, antioxidant, anti-proliferative, and anti-inflammatory activities [20]. KA also acts as a UV protector and suppressor of skin hyper-pigmentation owing to its tyrosinase inhibitory activity [21].

Egyptian soil is an under-explored resource for PL inhibitors. We aimed to isolate and identify soil fungal lipase inhibitor producer(s) and test the lipase inhibitor effect by in vitro and in vivo assays. The bioactive compound, from the most potent isolate, was further purified and characterized.

\section{Results}

Screening soil samples for possible fungal PL inhibitory effect The methanolic extracts of 39 mycelial mats, resulting from culturing soil samples in starch casein broth, were tested for PL inhibitory activity by the quantitative lipase colorimetric assay, using the substrate p-nitrophenyl palmitate and orlistat as a positive control. Fifteen soil samples showed PL inhibitory activity; all of which were agriculture field or garden soils (Table 1).

\section{Isolation and identification of PL inhibitor producers from soil sample S34}

We isolated three different fungal isolates from the soil sample, S34, recording the highest percentage of PL inhibition. We tested the methanolic extract of each of them for PL inhibitory activity. The isolate (AspsarO) showed a percentage PL inhibition of $35.5 \% \pm 3.0$ compared to orlistat $(41 \% \pm$ $2.45)$ with no significant difference between them $(p>0.05)$. For further confirmation of PL inhibition, the $100 \%$ methanolic fraction of AspsarO extract was retested by a fluorometric assay using the substrate 4-methyl-umbelliferyl butyrate. There was no significant difference between the percentage of PL inhibition by AspsarO $(20 \% \pm 4.583)$ and orlistat $(19.67 \% \pm 4.485)(p>0.05)$. These findings suggested that AspsarO is a possible PL inhibitor producer.

To identify AspsarO, the macromorphological characteristics of its colonies on PDA, CYA, and MEA were examined. On both PDA and MEA, AspsarO colonies were yellowish-green with white mycelia at the edges, while the colonies on CYA were yellow at the center with white mycelia at the edges. The conidia were rough and did not produce any exudates or soluble pigments in the tested media (Supplementary Figure 1). The micromorphological features of AspsarO, conidia heads, and conidia are shown in Supplementary Figure 2. These findings suggest that AspsarO belonged to the Aspergillus species. Also, $18 \mathrm{~S}$ rDNA sequencing was performed for the molecular identification of AspsarO. The obtained sequence was blasted against the nucleotide database using blastn tool, of the US National Centre for Biotechnology Information (NCBI), and showed $100 \%$ identity to Aspergillus oryzae RIB40 DNA, chromosome 7 (NC_036441.1). It was deposited in GenBank under GenBank accession no. (MT334462). We constructed a phylogenetic tree based on 185 rDNA sequence of AspsarO and the closely related species using MEGA-X (Fig. 1) and this further confirmed the identification.

\section{Optimization of lipase inhibitor production by AspsarO}

We used sequential optimization approaches. A onevariable-at-a time method was used for the determination of the optimum factors for PL inhibitor production by AspsarO. This was followed by testing different combinations of factors using a multifactorial design. 
Table 1 Screening crude soil mycelial extracts for PL inhibitory activity

\begin{tabular}{|c|c|c|c|}
\hline Sample number & Type of soil & Area of collection & $\%$ PL inhibition \\
\hline S1 & Agriculture field & Monofiya & 0 \\
\hline S2 & Agriculture field & Monofiya & 13 \\
\hline S3 & Agriculture field & Monofiya & 1.3 \\
\hline S4 & Agriculture field & Monofiya & 10.1 \\
\hline S5 & Agriculture field & Monofiya & 4.7 \\
\hline S6 & Agriculture field & Monofiya & 17.2 \\
\hline S7 & Garden & Cairo & 6 \\
\hline S8 & Garden & Cairo & 6.3 \\
\hline 59 & Agriculture field & Monofiya & 0 \\
\hline $\mathrm{S} 10$ & Agriculture field & Monofiya & 0 \\
\hline S11 & Garden & Elein Elsokhna & 13.3 \\
\hline $\mathrm{S} 12$ & Garden & Elein Elsokhna & 0 \\
\hline $\mathrm{S} 13$ & Garden & Elein Elsokhna & 0 \\
\hline S14 & Garden & Elein Elsokhna & 0 \\
\hline S15 & Garden & Elein Elsokhna & 0 \\
\hline S16 & Sandy & Elein Elsokhna & 0 \\
\hline S17 & Sandy & Elein Elsokhna & 0 \\
\hline $\mathrm{S} 18$ & Sandy & Elein Elsokhna & 0 \\
\hline S19 & Sandy & Elein Elsokhna & 0 \\
\hline S20 & Soil (sewer) & Cairo, magraeloyon & 0 \\
\hline S21 & Soil (sewer) & Cairo, magraeloyon & 0 \\
\hline S22 & Soil (sewer) & Cairo, magraeloyon & 0 \\
\hline S23 & Soil (sewer) & Cairo, magraeloyon & 13.3 \\
\hline S24 & Nile river bank & Cairo & 0 \\
\hline S25 & Nile river bank & Cairo & 0 \\
\hline S26 & Nile river bank & Cairo, Helwan & 0 \\
\hline S27 & Nile river bank & Cairo, Helwan & 0 \\
\hline S28 & Garden & Kanater & 0 \\
\hline S29 & Garden & Warraa & 0 \\
\hline S30 & Garden & Monofiya & 0 \\
\hline S31 & Garden & Monofiya & 0 \\
\hline S32 & Garden & Monofiya & 0 \\
\hline S33 & Garden & Monofiya & 16.3 \\
\hline S34 & Agriculture field & Giza, Saftlabban & 46 \\
\hline S35 & Agriculture field & Giza, Saftlabban & 0 \\
\hline S36 & Agriculture field & Giza, Saftlabban & 12 \\
\hline S37 & Agriculture field & Giza, Saftlabban & 2.8 \\
\hline S38 & Garden & Cairo, Nasr city & 11.8 \\
\hline S39 & Garden & Cairo, Garden city & 8.9 \\
\hline
\end{tabular}

\section{Factors affecting PL inhibitor production}

The percentage PL inhibition was determined following the incubation of AspsarO under different incubation temperatures and time, using alternative carbon sources and different nitrogen supplements in the fermentation medium. PL inhibitor production increased by increasing the incubation temperature with the highest yield recorded at $37^{\circ} \mathrm{C}$ (Fig. 2-a). Also, it increased by prolonging the incubation time with the optimum production recorded on day six (Fig. 2-b). Replacing dextrose in 


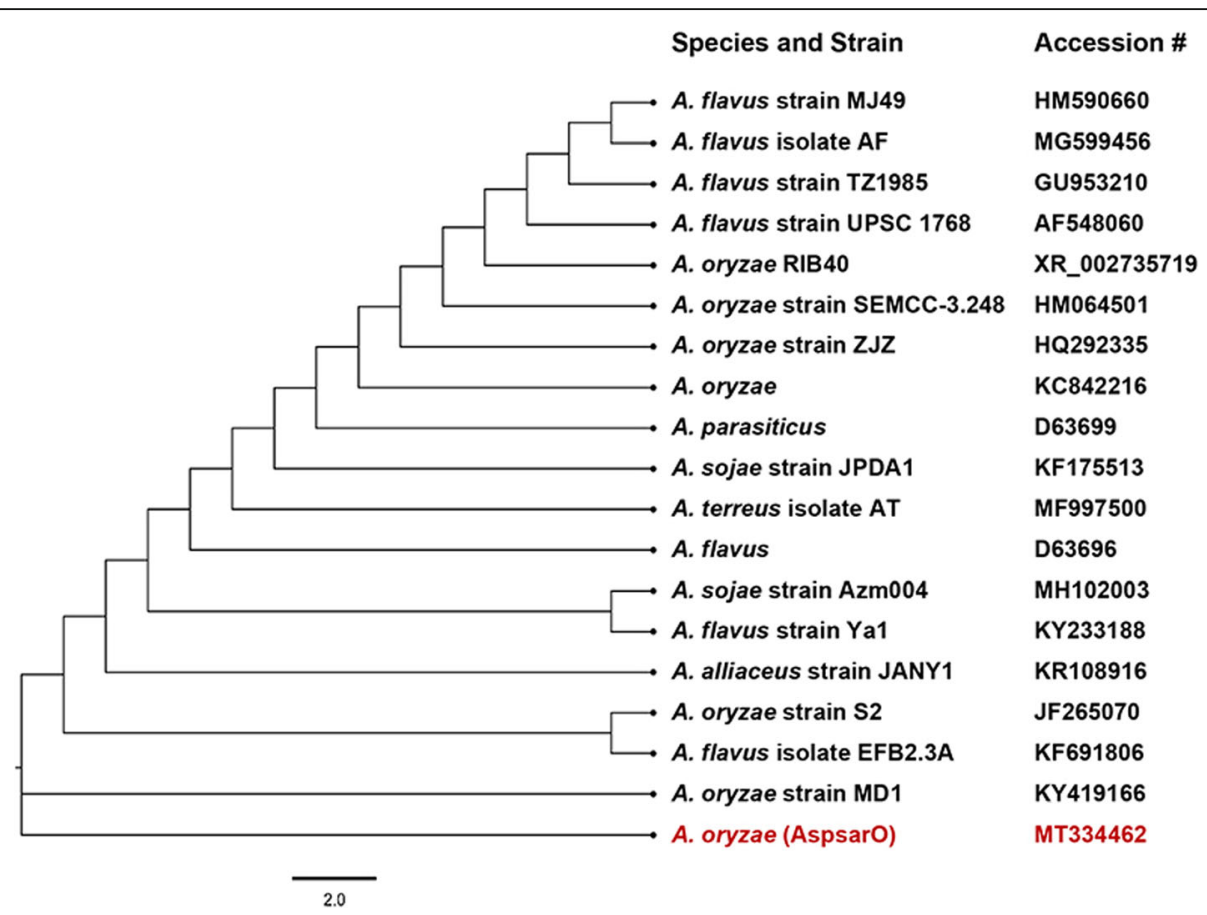

Fig. 1 Phylogenetic tree for AspsarO, based on 185 rDNA sequence analysis using the maximum composite likelihood method. The tree was constructed using MEGA-X, where the evolution distances from hypothetical ancestors are represented by nodes between the AspsarO isolate and closely related Aspergilli. AspsarO partial 185 rDNA was deposited in Genbank under accession no. MT334462
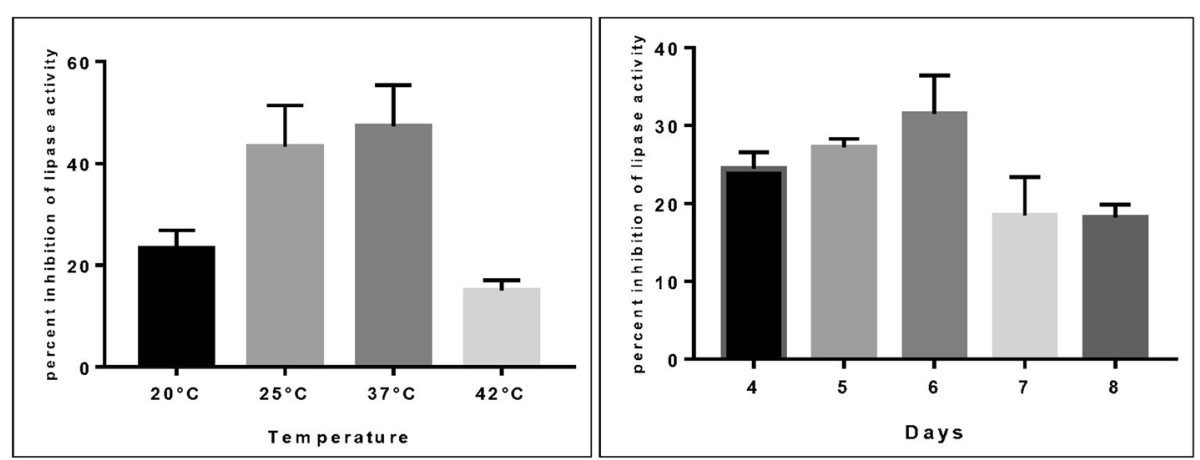

a

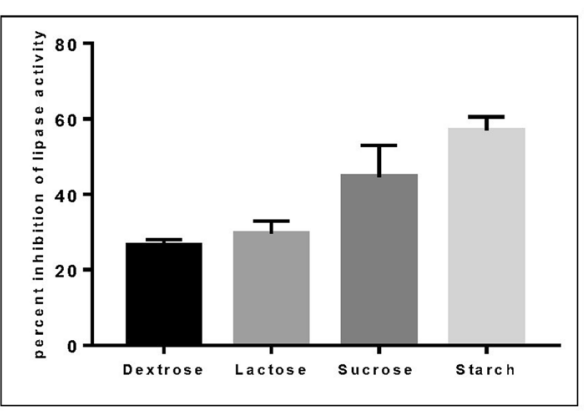

c

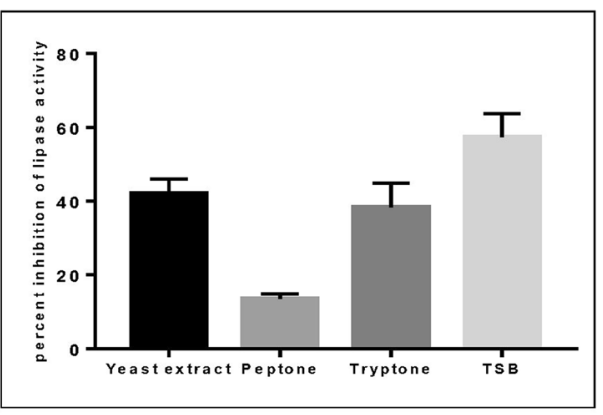

d

Fig. 2 Optimization of lipase inhibitor production by AspsarO where: a Different incubation temperatures in PDB for 6 days. $\mathbf{b}$ Incubation time at $30^{\circ} \mathrm{C}$ in PDB. c Different carbon sources in potato broth cultures at $30^{\circ} \mathrm{C}$ for 6 days. d Different nitrogen sources in PDB at $30^{\circ} \mathrm{C}$ for 6 days. The data presented are the mean of three independent experiments, and the error bars represent the standard deviation (SD) 
PDB with starch almost doubled the PL inhibitor activity (Fig. 2-c); PDB with tryptic soy broth produced approximately 1.5 times the amount of PL inhibitor compared to PDB (Fig. 2-d).

\section{Multi-factorial design}

Lipase inhibitor production was optimized by testing a combination of factors using a multi-factorial design (Plackett-Burman design). The standardized effect of each factor (E-value) was calculated using Minitab software (version 18), and the E-value of the measured response was recorded as percentage PL inhibition (Table 2).

The value of the predicted determination coefficient $\left(\mathrm{R}^{2}{ }_{\text {Pred }}\right)$ was 0.84 , and the adjusted determination coefficient $\left(R_{\text {Adj }}^{2}\right)$ was 0.90 . The Pareto chart showed the standardized effect, magnitude and significance of each factor (Fig. 3). Percentage PL inhibition ranged from 25.9 to $61.4 \%$, with the highest percentage recorded by increasing the incubation time and temperature. Normal probability plot of residuals examined the goodness of the model fit (Fig. 4), and the residuals were normally distributed. The main effect plot determined the main effects of all factors; it revealed that PL inhibitor production was influenced by both incubation time and temperature (Fig. 5). Thus, the incubation time and temperature significantly affect the response, while the carbon and nitrogen sources are non-significant factors.
Purification and characterization of the active PL inhibitor AspsarO was inoculated in eight liters potato starch broth supplemented with tryptic soy broth and incubated at $37^{\circ} \mathrm{C}$ for 6 days for maximum PL inhibitor production. The biomass was separated from the cultured broth, which was subjected to fractionation using methylene chloride. The remaining aqueous layer was concentrated under vacuum and applied to a DiAION HP-20 column.

Percentage of PL inhibition by the AspsarO fractions were $23,0,36$, and $43 \%$ for the methylene chloride, aqueous, 50, and $100 \%$ methanolic fractions, respectively. Purification, of the $100 \%$ methanolic fraction, was performed using bio-guided chromatographic techniques. This resulted in the isolation of kojic acid as the main constituent of the fraction. The identity of the compound (off-white amorphous powder) was confirmed by ${ }^{1} \mathrm{H}$ NMR spectral data $\left(\mathrm{CD}_{3} \mathrm{OD}, 400 \mathrm{MHz}\right)$; $4.35(2 \mathrm{H}, \mathrm{s}, \mathrm{H}-7), 6.39(1 \mathrm{H}, \mathrm{s}, \mathrm{H} 3), 7.85(1 \mathrm{H}, \mathrm{s}, \mathrm{H} 6)$ and ${ }^{13} \mathrm{C}$ NMR spectral data $\left(\mathrm{CD}_{3} \mathrm{OD}, 100 \mathrm{MHz}\right) ; 59.8(\mathrm{C} 7)$, 110.1 (C3), 139.6 (C6), 146.0 (C5), 170.0 (C2), 175.5 (C4), and by comparison to literature [22].

\section{Molecular docking study}

The binding modes and affinities of kojic acid, within the binding site of the human pancreatic lipase enzyme, was predicted using molecular docking. Self-docking of the co-crystallized ligand, B-Octylglucoside (BOG), of

Table 2 Placket-Burman design matrix for determination of optimum conditions for PL inhibitor production by AspsarO

\begin{tabular}{|c|c|c|c|c|c|}
\hline \multirow[t]{2}{*}{ Runs } & \multicolumn{4}{|l|}{ Factors } & \multirow{2}{*}{$\begin{array}{l}\text { Response }^{c} \\
\% \mathrm{PL} \text { inhibition } \pm \text { SD }\end{array}$} \\
\hline & $\begin{array}{l}\text { Incubation Temperature } \\
\left({ }^{\circ} \mathrm{C}\right)\end{array}$ & $\begin{array}{l}\text { Production time } \\
\text { in Days }\end{array}$ & $\begin{array}{l}\text { Carbon source replacing } \\
\text { dextrose in PDB }\end{array}$ & $\begin{array}{l}\text { Nitrogen } \\
\text { source }\end{array}$ & \\
\hline 1 & 25 & 5 & sucrose & $Y E^{a}$ & $44.8 \pm 3.3$ \\
\hline 2 & 37 & 5 & sucrose & YE & $48.0 \pm 2.6$ \\
\hline 3 & 25 & 6 & sucrose & YE & $50.0 \pm 2.6$ \\
\hline 4 & 37 & 6 & sucrose & YE & $53.1 \pm 4.1$ \\
\hline 5 & 25 & 5 & starch & YE & $47.9 \pm 1.4$ \\
\hline 6 & 37 & 5 & starch & YE & $46.1 \pm 1.1$ \\
\hline 7 & 25 & 6 & starch & YE & $56.4 \pm 0.9$ \\
\hline 8 & 37 & 6 & starch & YE & $48.0 \pm 1.2$ \\
\hline 9 & 25 & 5 & sucrose & $\mathrm{TSB}^{\mathrm{b}}$ & $48.2 \pm 3.3$ \\
\hline 10 & 37 & 5 & sucrose & TSB & $38.9 \pm 0.9$ \\
\hline 11 & 25 & 6 & sucrose & TSB & $51.7 \pm 5.7$ \\
\hline 12 & 37 & 6 & sucrose & TSB & $56.6 \pm 2.0$ \\
\hline 13 & 25 & 5 & starch & TSB & $25.9 \pm 2.4$ \\
\hline 14 & 37 & 5 & starch & TSB & $51.2 \pm 0.7$ \\
\hline 15 & 25 & 6 & starch & TSB & $57.5 \pm 2.3$ \\
\hline 16 & 37 & 6 & starch & TSB & $61.4 \pm 1.8$ \\
\hline 17 & 25 & 5 & - & - & $43.3 \pm 8.0$ \\
\hline
\end{tabular}

a yeast extract, ${ }^{b}$ tryptic soy broth. ${ }^{\mathrm{c}}$ All runs were performed in triplicates; the response is represented as the mean of three independent experiments \pm the standard deviation 


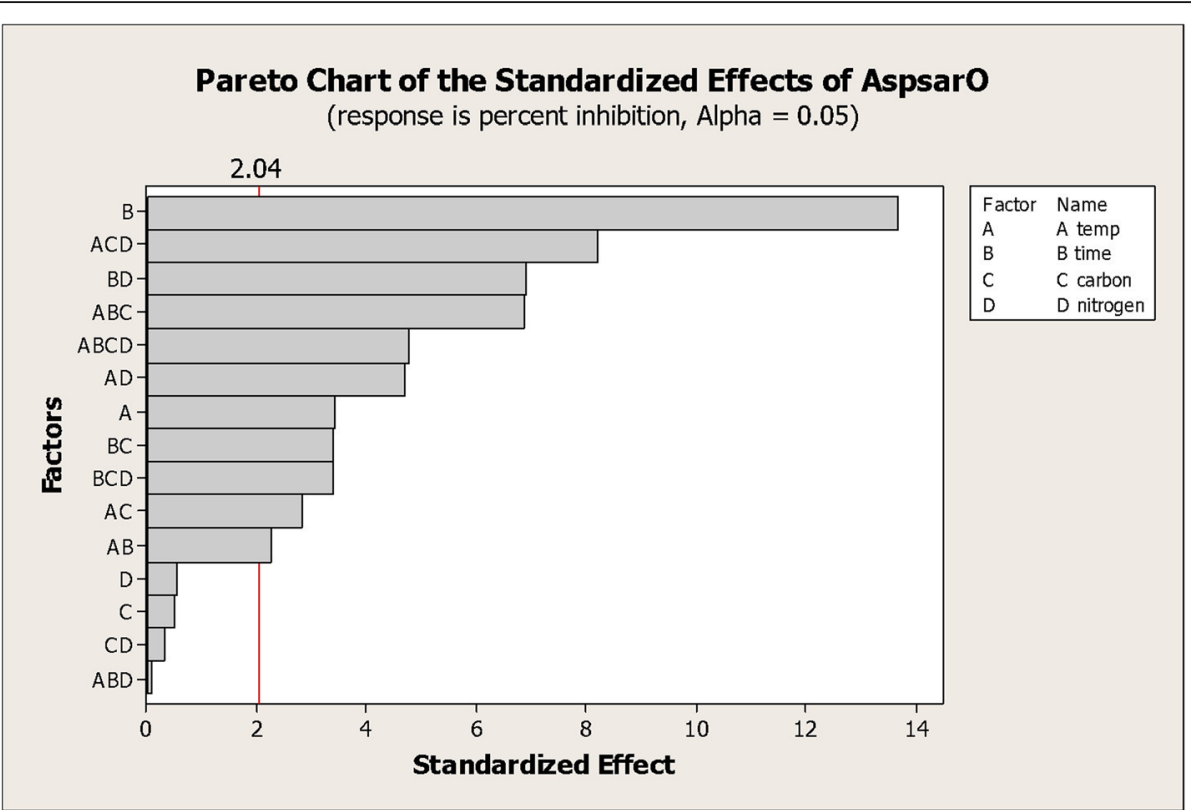

Fig. 3 Pareto chart ranking the standardized effects of different variables on lipase inhibitory activity. The vertical line in chart represents a reference line, any factor that exceeds this line is of significant effect at alpha $=0.05$ (significance level). Incubation time and temperature significantly affected the inhibitor production

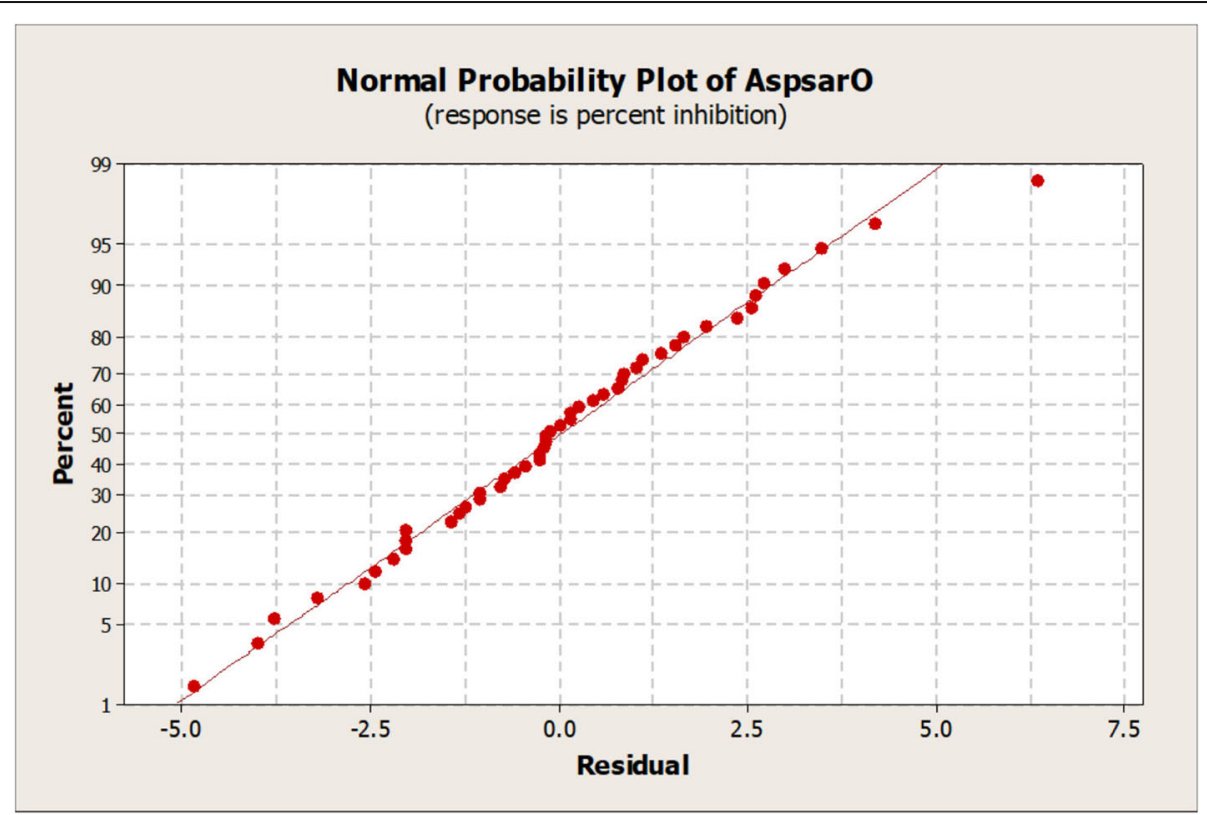

Fig. 4 Normal probability plot of residuals by AspsarO. The straight line in the graph represents the mathematical regression equation (which determines the expected data), while the dots in the plots represent the actual observed data. As shown in figure, the dots generally formed a line consistent with regression line, therefore the residuals (the difference between observed data and expected data) are considered normally distributed 


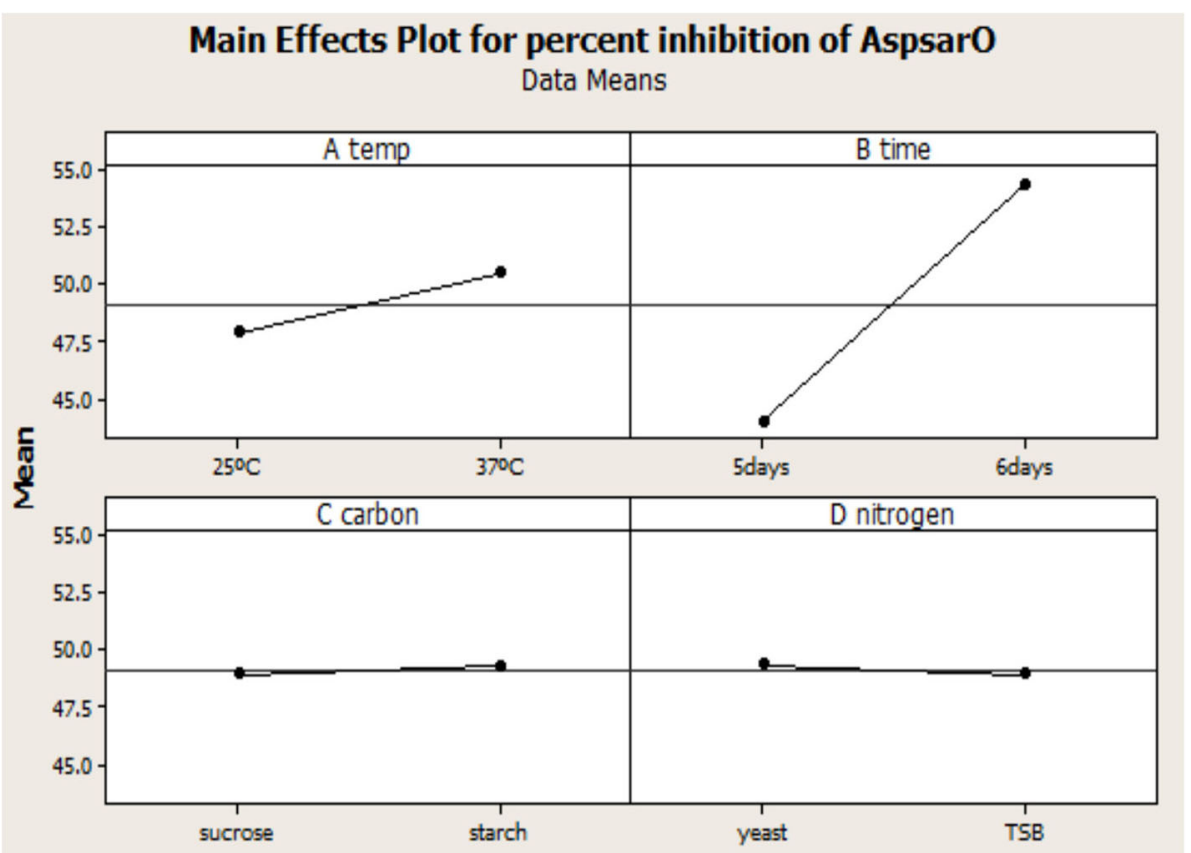

Fig. 5 Main effect plot comparing the magnitude of the main effects of factors. The steeper the slope of the line is, the greater the magnitude of the main effect. When the line is horizontal (parallel to the $x$-axis), no main effect is present. Incubation time and temperature affected lipase inhibitor production

PL enzyme in the vicinity of its binding site was validated in docking setup (Fig. 6-a). BOG docking pose interactions with the key amino acids (Lys80, Glu83, and Asn84), in PL binding site, recorded a score of -5.4529 $\mathrm{kcal} / \mathrm{mol}$. The superimposition of the co-crystallized (red) and the docking pose (green) of BOG in PL binding site was with an RMSD of $2.0834 \mathrm{~A}^{\circ}$ (Fig. 7).

We used the validated setup for predicting the mode of interaction of kojic acid, and orlistat (binding ligands) to PL binding site (receptor). The activity of kojic acid is attributed to its interaction with the key amino acids in PL binding site and having comparable docking pattern and scores to the co-crystallized ligand. The results are summarized in Table 3, and Fig. 6-b and c).

\section{Half maximal inhibitory concentration $\left(\mathrm{IC}_{50}\right)$}

PL inhibitory activity of different concentrations $(1,5$, $10,25,50$, and $100 \mu \mathrm{g} / \mathrm{ml}$ ) of the dried $100 \%$ methanolic fraction of AspsarO, kojic acid, and orlistat was determined. The $\mathrm{IC}_{50}$ of the dried $100 \%$ methanolic fraction of AspsarO, kojic acid and orlistat was $7.48 \mu \mathrm{g} / \mathrm{ml}$, $6.62 \mu \mathrm{g} / \mathrm{ml}$, and $3.72 \mu \mathrm{g} / \mathrm{ml}$, respectively.

\section{Evaluation of the PL inhibitory activity of $100 \%$} methanolic fraction of AspsarO in a high-fat diet induced obesity animal model

Increased single oral doses, of the dried 100\% methanolic fraction, of AspsarO up to $1000 \mathrm{mg} / \mathrm{kg}$ were administered to Sprague-Dawley rats. No unusual changes in behaviour, locomotor activity, or signs of intoxication, and mortality were observed, during the 28day study period, showing the safety of the tested agent.

Administration of a high-fat diet (HFD) to SpragueDawley rats, for 28 days, resulted in a significant increase in the percentage weight gain in the HFD-fed group (19.2\%) compared to the control group on a normal diet $(6.7 \%)(p<0.05)$ (Fig. 8-a). The tested extract $(100 \mathrm{mg} /$ $\mathrm{kg}$ ) caused a slight decrease in weight gain in the HFDfed treated group (16.7\%) compared to the HFD-fed control group (19.2\%). Throughout the study, rats on a HFD consumed significantly less food than those on a normal diet $(p<0.05)$. Administration of AspsarO extract significantly reduced the food intake by the HFDfed treated group compared to HFD-fed control group $(p<0.05)$ (Fig. 8-b). AspsarO extract has an appetite suppressant effect that could contribute to its antiobesity action.

A high-fat diet caused a significant increase in serum triglycerides (TG), and total cholesterol (TC) in the HFD-fed group $(p<0.05)$. The augmented TG levels were significantly lower in AspsarO HFD-fed treated compared to the HFD-fed control group $(p<0.05)$. The TC levels were slightly lower in AspsarO HFD-fed treated compared to the HFD-fed control group (Fig. 8c, and d). Administration of a HFD for 4 weeks resulted in a significant increase in rats' liver weight $(p<0.05)$, 


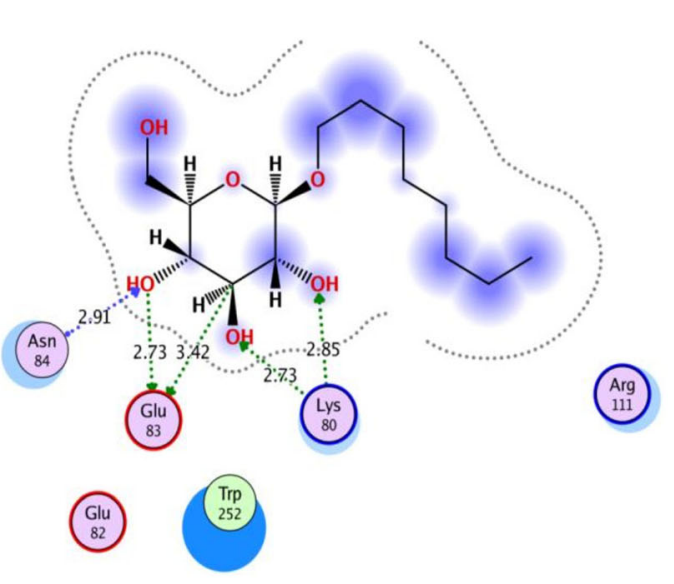

a

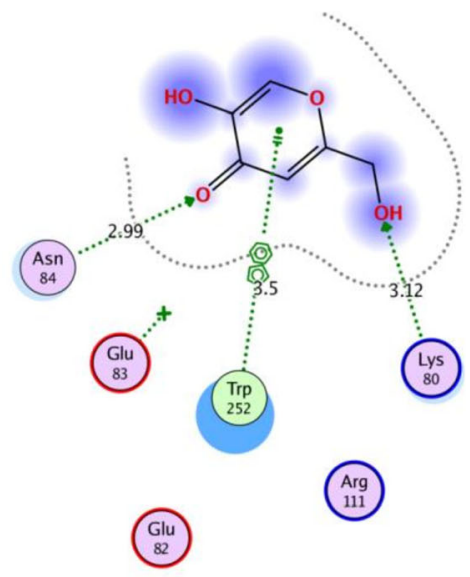

b

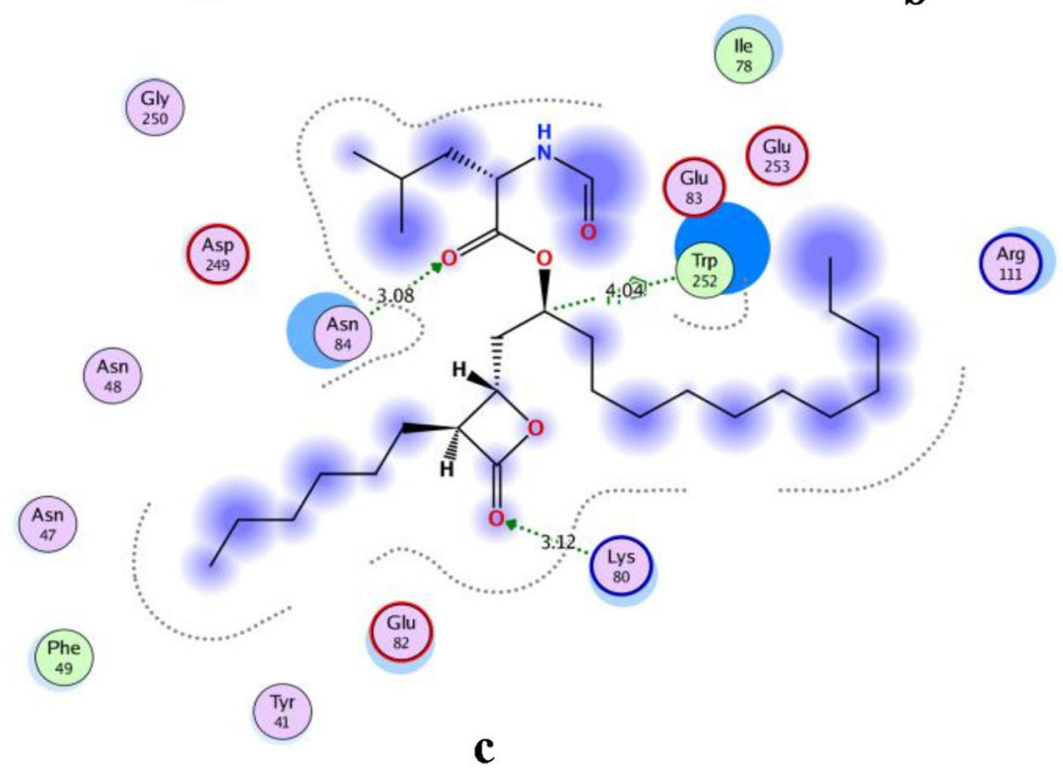

Fig. 6 2D docking pose interaction diagrams with the key amino acids in human PL binding site. a BOG, b Kojic acid and c Orlistat

while treatment with AspsarO extract resulted in a much lower increase in liver weight compared to the HFD-fed control rats (Fig. 8-e).

\section{Discussion}

Obesity is a global health concern affecting both developing and developed countries [5]. It is correlated with the leading causes of death worldwide [11]. PL inhibitors can suppress weight gain in obese subjects [23]. Egyptian soil fungi are an under-explored resource for screening potential PL inhibitors. In this study, soil samples were collected and tested for lipase inhibition activity. PL inhibitor producers were isolated, identified, and tested in an induced obesity animal model. The active extract was further subjected to fractionation, purification, and characterization to determine the chemical structure of the active metabolite.
Thirty-nine soil samples were collected from different areas in Egypt; $38.5 \%$ of the samples showed PL inhibition activity, $66.67 \%$ of which were agriculture soils. This is in accordance with previous studies from India that reported the isolation of $\mathrm{PL}$ inhibitor producers from field soils $[24,25]$. In our study, the active PL inhibitor producer (AspsarO) was identified as Aspergillus oryzae based on its colony morphology, microscopical characteristics together with $18 S$ rDNA sequencing. Despite the availability of molecular methods, that are advancing the identification of Aspergillus, the morphological method remains the most used tool for identification [26].

The quantitative lipase colorimetric assay, to measure PL inhibitory activity, was used to determine the $\mathrm{IC}_{50}$, which was $7.48 \mu \mathrm{g} / \mathrm{ml}$ in case of the $100 \%$ methanolic fraction of AspsarO extract compared to orlistat 


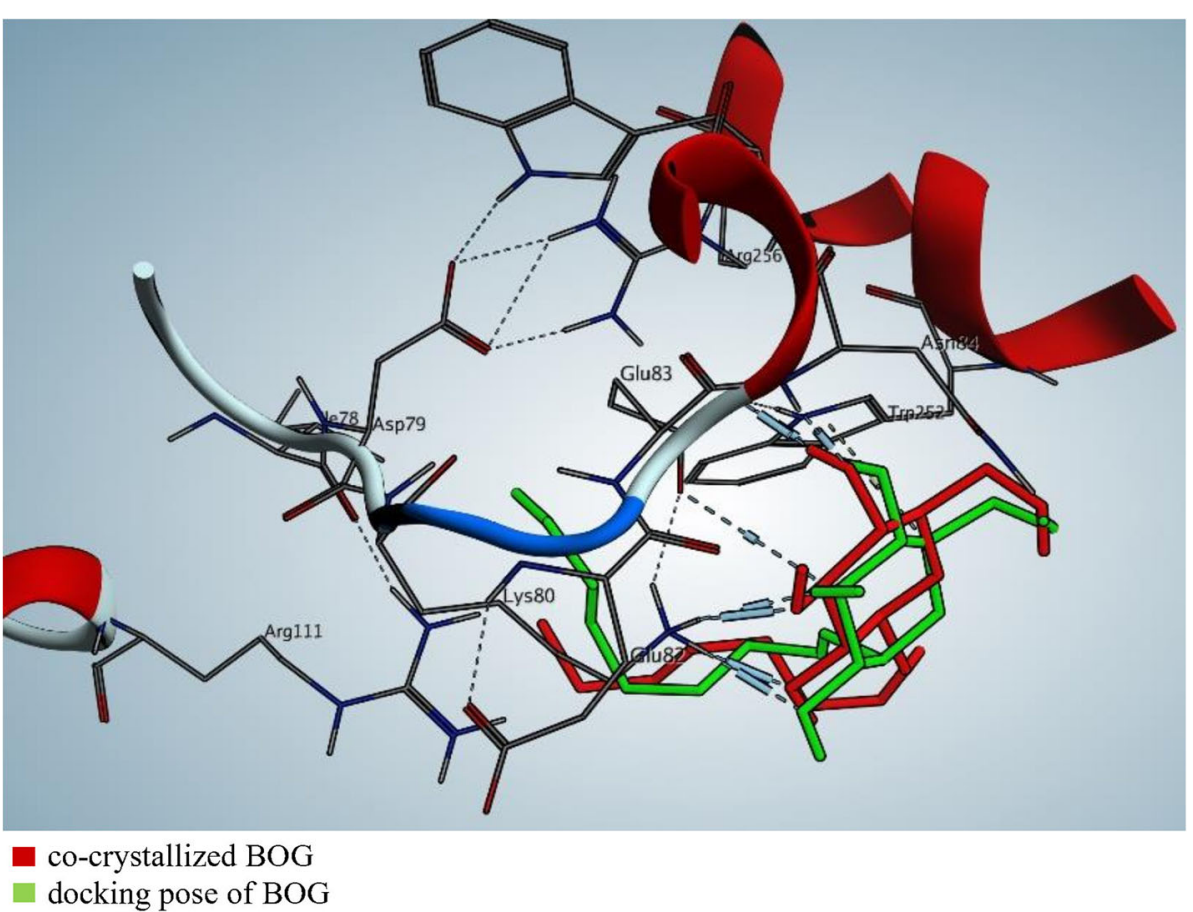

Fig. 7 3D superimposition of the co-crystallized and the docking pose of BOG in PL binding site. The superimposition of the co-crystallized BOG in pancreatic lipase binding site is represented in red color and its docking pose is represented in green color; the superimposition was with RMSD of $2.0834 \mathrm{~A}^{\circ}$

$(3.72 \mu \mathrm{g} / \mathrm{ml})$. The $100 \%$ methanolic fraction of AspsarO was further purified by bio-guided chromatographic techniques. The active metabolite was analyzed by ${ }^{1} \mathrm{H}$ and ${ }^{13} \mathrm{C}$ NMR, to confirm its structure, and was identified as kojic acid $\left(\mathrm{IC}_{50}\right.$ of $\left.6.62 \mu \mathrm{g} / \mathrm{ml}\right)$. Several studies reported the production of kojic acid by Aspergillus oryzae [20] and other soil fungi [27]. Docking studies revealed the ability of kojic acid to interact with the key amino acids in the binding site of PL similarly to the well-known standard inhibitor (orlistat) and this supports its activity. Ruilin and coworkers used the same docking approach to suggest the PL inhibitory effect of the decapeptide PP1 (Leu-Leu-ValVal-Try-Pro-Trp-Thr-Gln-Arg) using orlistat and simvastatin as positive controls [23].

Several studies reported fungal PL inhibitors, including vibralactone isolated from Boreostereum vibrans [28].
The endophytic extracts from Viola odorata exhibited good to moderate $\left(\mathrm{IC}_{50}<10 \mu \mathrm{g} / \mathrm{ml}\right.$ to $10-20 \mu \mathrm{g} / \mathrm{ml}$ ) PL inhibitory activity. VOLF4 (Aspergillus sp.), VOLF5 (Peniophora sp.), and VOR5 (Fusarium nematophilum) extracts exhibited PL inhibitory activity with an $\mathrm{IC}_{50}$ of $3.80 \mu \mathrm{g} / \mathrm{ml}, 5.85 \mu \mathrm{g} / \mathrm{ml}$, and $6.52 \mu \mathrm{g} / \mathrm{ml}$, respectively [8]. The ethyl acetate extract of the endophytes \#57TBBALM (Penicillium sp.), and \#AMLWLS (Fusarium sp.) isolated from Aegle marmelos, and Taxus baccata, respectively, had good PL inhibitory activity $\left(\mathrm{IC}_{50}\right.$ 3.69 , and $2.12 \mu \mathrm{g} / \mathrm{ml})[7,12]$.

A multi-factorial, Plackett-Burman, design allows performing a minimum collection of experimental runs, to screen for significant factors. A linear correlation between the response and a variable is sufficient for screening the main variables [29]. Our tested factors

Table 3 Docking results of kojic acid and orlistat with the human pancreatic lipase enzyme

\begin{tabular}{|c|c|c|c|c|c|}
\hline Compound & $\mathrm{S}$ (kcal/mol) & Amino acids & Interacting groups & Type of interaction & Length \\
\hline \multirow[t]{3}{*}{ Kojic acid } & -3.6920 & Lys80 & $\mathrm{OH}$ & H-bond (acceptor) & 3.12 \\
\hline & & Asn84 & $\mathrm{O}(\mathrm{C}=\mathrm{O})$ & H-bond (acceptor) & 2.99 \\
\hline & & Trp252 & Pyranone & Arene-Arene & 3.50 \\
\hline \multirow[t]{3}{*}{ Orlistat } & -6.3694 & Lys80 & O (lactone & H-bond (acceptor) & 3.12 \\
\hline & & Asn84 & $C=O)$ & H-bond (acceptor) & 3.08 \\
\hline & & Trp252 & $\begin{array}{l}\mathrm{O} \text { (ester } \mathrm{C}=\mathrm{O} \text { ) } \\
\mathrm{CH}\end{array}$ & Arene-H & 4.04 \\
\hline
\end{tabular}



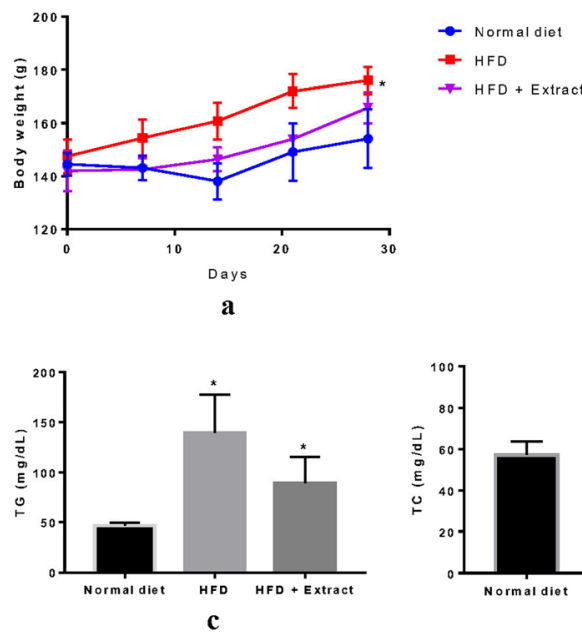
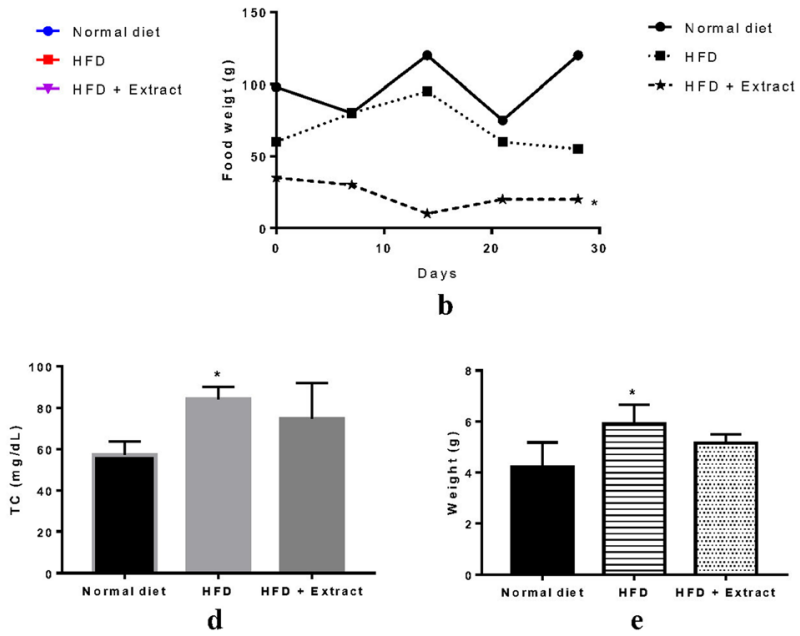

Fig. 8 Effects of 100\% methanolic extract of AspsarO on a HFD obesity-induced animal model where: a Average body weight vs. time, b Food consumption, c Serum triglyceride levels (TG) levels, d Serum total cholesterol (TC) levels and e Liver weight, of rats on a normal diet, HFD-fed and AspsarO treated HFD-fed rats for 4 weeks (one-way ANOVA, Holm-Sidak post hoc test, $n=5$ per group)

were, previously, reported to have an influence on kojic acid production [30]. The percentage of PL inhibition from the tested Plackett-Burman runs ranged from 25.9 to $61.4 \%$. The regression equation was significant where the predicted $\mathrm{R}$ square value was close to the adjusted $\mathrm{R}$ square value, and this is an accurate measure of precision [31]. Based on our results, both incubation time and temperature significantly affected the response. The favorable temperature for PL inhibitor production was $37^{\circ} \mathrm{C}$, and the yield increased with time, reaching an optimum level on day six and decreased thereafter. This is comparable to a study by Azzahra and coworkers, who reported higher production of kojic acid in A. oryzae cultures incubated at $35^{\circ} \mathrm{C}$ for 7 days [32].

Percentage PL inhibition was doubled when using $2 \%$ starch as carbon source; this agrees with a previous study that reported increased production of kojic acid, by $A$. flavus strain (S33-2), when using corn starch in its culture [33]. This is attributed to the production of amylolytic enzymes during the growth of A. flavus strain S33-2, which hydrolyses starch causing an increase in glucose concentration in cultures. Glucose has a sixcarbon ring and acts as a precursor for kojic acid synthesis [34]. Similarly, corn starch was previously reported to be the optimum carbon source for kojic acid production by $A$. oryzae; using $10 \%(\mathrm{w} / \mathrm{v})$ corn starch and yeast extract in $A$. oryzae cultures produced the highest yield [35]. In our study, supplementing cultures with tryptic soy broth resulted in an enhanced PL inhibitor production. Tryptic soy broth is a nutritious medium that provides amino acids, and other complex nitrogenous substances, besides glucose which is a source of energy. The presence of important growth factors, such as vitamins, and oligo-elements in specific nitrogen sources play an important role in enhancing kojic acid production [36]. On the contrary, yeast extract was reported to be the most favorable organic nitrogen source, for kojic acid production, compared to peptone and polypeptone [37]; others proposed peptone [33]. A previous study suggested the optimal medium, for fermentation of kojic acid using $A$. oryzae, to contain sucrose and yeast extract [32].

To develop effective anti-obesity treatments, various obesity-induced animal models are utilized to emulate obesity-like conditions in humans [38]. HFD feeding to Sprague-Dawley rats for 4 weeks resulted in obesity-like conditions with a significant increase in body weight, liver weight, and serum lipid levels. This agrees with previous studies reporting the usefulness of HFD-fed rats' obesity-induced model [38]. Treatment with dried 100\% methanolic fraction of AspsarO extract, at a daily dose of $100 \mathrm{mg} / \mathrm{kg}$, resulted in a decrease in percentage weight gain of HFD-fed rats; suggesting an anti-obesity effect. Similarly, feeding rats a cafeteria diet (CD) for 6 weeks resulted in obesity-like conditions with increased body weight, liver weight, and serum lipids. Treatment with galangin, a PL inhibitor isolated from Alpinia galangal rhizomes at a dose of $50 \mathrm{mg} / \mathrm{kg} / \mathrm{d}$, resulted in a significant decrease in weight gain in CD-fed rats, indicating an anti-obesity effect [38].

Obvious suppression in appetite, with a significant decrease in food intake, was observed in AspsarO HFD-fed treated group, and this could account for the decreased percentage in weight gain. Previous reports highlighting the reduction in food intake and a decrease in body weight in HFD-fed mice and rats, receiving herb or plant extracts having a PL inhibitory effect, are available. This was attributed to metabolic changes, alteration in 
appetite-related peptides' expression, or altered energy expenditure because of treatment [39].

In obese cases, the liver receives larger amounts of fatty acids; this increases its weight and accumulates the lipids in it due to the possibility of impairment of normal lipids' catabolism [40]. In our study, a significant increase in liver weight was observed in the HFD-fed group compared to the group on a normal diet. Administration of AspsarO extract reduced the increase in liver weight in HFD-fed treated group. This effect is probably due to the inhibition of lipase activity. Also, a significant increase in serum lipids, such as TC and TG, was observed in HFD-fed rats. Treatment with the AspsarO extract resulted in a significant decrease in serum TG, and this suggests an anti-triglyceride effect with possible cardioprotective activity. A previous study reported a significant decrease in serum TG, TC, and LDL-C upon administering, a daily dose of 35 or $70 \mathrm{mg} / \mathrm{kg}$, platycodin saponin (PL inhibitor) to HFD-fed Sprague-Dawley rats for 4 weeks [41]. Similarly, HFD-fed Sprague-Dawley rats receiving a mixture of an aqueous extract of Salacia reticulata and cyclodextrin had lower plasma triacylglycerol levels, body weight, and visceral fat mass compared to the HFD-fed control group. This is due to its polyphenolic constituents, with lipase-inhibitory activity, resulting in a decrease in lipid absorption from the small intestine [39]. The anti-obesity activity of rice koji molds, mostly A. oryzae, was evaluated in HFD obesity-induced animal models. Kojic acid and pyranonigrin-A are among the secondary metabolites of koji molds [42, 43]. Rice koji decreased weight gain [44], total adipose tissue [44], liver weight [45], serum TG levels [45] without affecting food intake [44] in rat obesity models; thus reducing the risk of arteriosclerosis [46]. This agrees with our observed anti-obesity and anti-triglyceride effects of kojic acid, but disagrees with the loss of appetite encountered in our study.

\section{Conclusions}

An A. oryzae local isolate, from agriculture soil, can be used for the production of kojic acid. The results of the obesity-induced animal model, in silico molecular docking, and the lipase inhibitory assay provide scientific evidence for the promising future use of kojic acid, in obesity management and as an anti-triglyceride agent.

\section{Methods}

\section{Collection of soil samples and isolation of fungal lipase inhibitor producer(s)}

Thirty-nine soil samples were collected from various ecosystems in Egypt: fields, gardens, Nile river bank areas from July 2017-January 2018 (Table 1). Lipase inhibitor active producers were isolated according to the method of Naveen and coworkers with some modifications where: one-gram soil sample was mixed with $100 \mathrm{ml}$ sterile distilled water with shaking at $10 \times \mathrm{g}$ for $1 \mathrm{~h}$ at $28^{\circ} \mathrm{C}$. One $\mathrm{ml}$ supernatant was inoculated in duplicate in $50 \mathrm{ml}$ starch casein broth and incubated at $28{ }^{\circ} \mathrm{C}$ for 7 days with shaking at $10 \times$ g. Following incubation, the mycelial mat was collected by centrifugation at $3000 \times \mathrm{g}$ for $20 \mathrm{~min}$ at $4{ }^{\circ} \mathrm{C}$. The mycelium was methanol extracted (1:4) and assayed for its lipase inhibitory activity. One $\mathrm{ml}$ culture, from the duplicate culture, was spread on starch casein agar and incubated at $28^{\circ} \mathrm{C}$ for 2 weeks. Colonies, recovered from samples having PL inhibitory activity, were further sub-cultured on starch casein agar followed by Sabouraud dextrose agar (Difco, USA) [47]. Isolated pure colonies were sub-cultured in starch casein broth for further testing their lipase inhibitor activity.

\section{Colorimetric pancreatic lipase $(\mathrm{PL})$ inhibition assay}

Pancreatic lipase (PL) inhibitory activity was measured colorimetrically using the substrate $p$-nitrophenyl palmitate (PNPP) (Sigma-Aldrich, USA), according to the method of Kordel and coworkers with slight modification where: the enzyme solution was prepared, immediately before use, by dissolving crude porcine PL type II (Sigma-Aldrich, EC 3.1.1.3, USA) in $100 \mathrm{mM}$ Tris (pH 8.2 ) to get a concentration of $2 \mathrm{mg} / \mathrm{ml}$ ( 200 units $/ \mathrm{ml}$ ). Ten $\mu \mathrm{L}$ methanolic extracts of the suspected cultures were pre-incubated with $40 \mu \mathrm{L}$ PL solution for $30 \mathrm{~min}$ at room temperature before the addition of $20 \mathrm{mM}$ PNPP dissolved in isopropanol [48]. The volume was adjusted to $200 \mu \mathrm{L}$ using $100 \mathrm{mM}$ Tris (pH 8.2), and the absorbance was measured at $410 \mathrm{~nm}$ using a spectrophotometer (Agilent Technologies, USA). The assay was performed in triplicates, and the results were expressed as an average mean value. Orlistat (Marcyrl pharmaceutical industries, Egypt), a known PL inhibitor, was used as a positive control; a control without the inhibitor was tested in parallel. The percentage of PL residual activity was determined for each extract by comparing the activity with and without the tested compounds. Percentage inhibition of lipase activity was calculated using the formula:

Lipase inhibition $=(A-B / A) \times 100$, where $A$ is lipase activity in the absence of inhibitor, $B$ is the lipase activity in the presence of inhibitor [49].

\section{Confirmatory fluorometric assay for lipase inhibition}

The pancreatic lipase inhibitory effect was further confirmed using a fluorometric assay where: $6.0 \mathrm{mg} 4$ methylumbelliferyl butyrate (MUB) (Sigma-Aldrich, USA) was dissolved in $1000 \mu \mathrm{l}$ DMSO and five-fold freshly diluted before the measurement. Ten $\mu \mathrm{l} 100 \%$ methanolic extract of the pure isolate, $90 \mu \mathrm{PL}$ enzyme $(0.2 \mu \mathrm{g} / \mathrm{ml})$, and $200 \mu \mathrm{l} 50 \mathrm{mM}$ phosphate buffer solution 
(pH 7.4) were added to a clear bottom black sides microtiter plate (Corning Incorporated, USA); $50 \mu \mathrm{l}$ MUB solution was added before measurement. Orlistat was used as a positive control. The emitted fluorescence at 445 $\mathrm{nm}$ was measured after excitation at $365 \mathrm{~nm}$ with a fluorescence spectrophotometer (Agilent Technologies, USA). The speed of fluorescence development is directly proportional to the product formation, and subsequently to PL activity. The assay was repeated three times, and the PL activity was measured with and without the inhibitor [9].

\section{Macroscopic and microscopic examination, $18 \mathrm{~S}$ based rDNA sequencing and phylogenetic analysis of the lipase inhibitor fungal producer}

Pure colonies, having lipase inhibitor activity, were subcultured on three culture media: potato dextrose agar (PDA) $(20 \%$ potato infusion, $2 \%$ dextrose, and $2 \%$ agar); malt extract agar (MEA) (2\% malt extract, and 1.2\% agar) and Czapek yeast extract agar (CYA) (0.3\% NaNO3, 3\% sucrose, 0.1\% K2HPO4, 0.05\% KCl, 0.001\% FeSO4 hydrated, $0.05 \%$ yeast extract, and $1.5 \%$ agar), and incubated at $25^{\circ} \mathrm{C}$ for 7 days. Macro and micromorphological characteristics were studied for identification to species level [26]. Colony morphology, color, size, and texture were examined. The microscopical characteristics: hyphae, conidiophores, and conidia were examined by the wet mount technique at $40 \mathrm{X}$ magnification by an Olympus microscope (Olympus Corporation, Japan) [50].

Genomic DNA extraction was performed as follows: $100-200 \mathrm{mg}$ mycelium was placed in a $1.5 \mathrm{ml}$ Eppendorf tube containing 100-150 $\mu \mathrm{l} 0.5 \mathrm{M} \mathrm{NaOH}$, quickly macerated with a micro-pestle (no big chunks) and allowed to stand for 6-10 min. $500 \mu \mathrm{l}$ Tris- $\mathrm{HCl}(100 \mathrm{mM}$, pH 8) was added followed by vortexing. After centrifugation for 10 min at 14,000 rpm, the supernatant was transferred to a new Eppendorf tube and stored at $-20^{\circ} \mathrm{C}$. One $\mu \mathrm{l}$ of the prepared DNA was used as a template in PCR reactions [51]. The PCR reaction was performed in a final reaction volume of $50 \mu \mathrm{l}$ using the primers: $18 \mathrm{~S} \mathrm{~F}\left(5^{\prime}\right.$ - tgatccttcygcaggttcac- $\left.3^{\prime}\right)$ and $18 S \mathrm{R}\left(5^{\prime}\right.$ - acctggttgatcctgccag- $\left.3^{\prime}\right)$ (Invitrogen, USA) at a concentration of $0.5 \mu \mathrm{M}$ each [52], $0.5 \mathrm{mM}$ dNTPs (Promega, USA), and $2 \mathrm{U}$ Taq DNA polymerase (Promega, USA) in $1 \times \mathrm{PCR}$ buffer (Promega, USA) containing $1.5 \mathrm{mM} \mathrm{MgCl}_{2}$ (Promega, USA), using a Techne thermal cycler (Cole-Parmer, USA). The cycling parameters were as follows: denaturation at $95^{\circ} \mathrm{C}$ for $5 \mathrm{~min} ; 30$ cycles each $94^{\circ} \mathrm{C}$ for $30 \mathrm{~s}$, $55^{\circ} \mathrm{C}$ for $1 \mathrm{~min}$, and $72^{\circ} \mathrm{C}$ for $2 \mathrm{~min}$; and a final extension at $72{ }^{\circ} \mathrm{C}$ for $10 \mathrm{~min}$. The amplified product was purified using Wizard SV Gel and PCR clean up system (Promega, USA), and sequenced using ABI3730XL sequencer (Macrogen, Korea). The obtained sequence was blasted against the nucleotide database using blastn tool of the US National Centre for Biotechnology Information (NCBI) [53].

Phylogenetic analysis was performed using MEGA-X software [54]. The obtained $18 S$ rDNA sequence of AspsarO and the downloaded sequences of its closely related neighbors were aligned using Clustal W. MUSCLE algorithm was used for trimming and verification of the aligned sequences. Maximum Composite Likelihood was used to compute the evolutionary distances [8].

\section{Optimization of lipase inhibitor production by AspsarO Incubation temperature and time}

To determine the optimum incubation temperature, a 5 $\mathrm{mm}$ mycelial plug of a seven-day-old AspsarO culture was inoculated in $250 \mathrm{ml}$ Erlenmeyer flasks containing $50 \mathrm{ml} \mathrm{PDB}$ and incubated at $20^{\circ} \mathrm{C}, 25^{\circ} \mathrm{C}, 37^{\circ} \mathrm{C}$, and $42{ }^{\circ} \mathrm{C}$ for 6 days with shaking at $5 \times$ g. On day six, the lipase inhibitory activity was measured [49]. As for the optimum incubation period, similar AspsarO cultures were incubated at $30^{\circ} \mathrm{C}$ for 8 days, and the lipase inhibitor activity was daily monitored starting from day four till the end of the experiment [49].

\section{Use of different carbon and nitrogen sources}

The effect of different carbon sources on lipase inhibitor production was studied by replacing dextrose in the culture medium (PDB) with each of the following sugars: $2 \%$ sucrose, $2 \%$ lactose, or $2 \%$ starch. Also, the effect of supplementing AspsarO cultures with different nitrogen sources was studied by adding $1 \%$ of each of the following: yeast extract, peptone, tryptone, or tryptic soy broth to the culture medium (PDP) [55]. A $5 \mathrm{~mm}$ mycelial plug of a seven-day-old AspsarO culture was inoculated in $250 \mathrm{ml}$ Erlenmeyer flasks containing $50 \mathrm{ml}$ culture medium and incubated at $30^{\circ} \mathrm{C}$ for 6 days with shaking at $5 \times$ g. The lipase inhibitor activity was measured on day six [49].

\section{Plackett-Burman design for optimization of PL inhibitor production}

A Plackett-Burman design was used to identify the main variables influencing lipase inhibitor production by AspsarO. Four independent variables, with the possible low $(-)$ and high $(+)$ levels, were assessed for their significance on the inhibitor yield. The tested variables included: carbon source ( $2 \%$ sucrose- $2 \%$ starch), nitrogen source ( $1 \%$ yeast extract-1\% tryptic soy broth), production time (5-6 days), and temperature $\left(25-37^{\circ} \mathrm{C}\right)$. Table 2 shows the tested medium ingredients and incubation conditions of the 16 runs of the assessed factors besides the 17th run under control conditions. Minitab 18 software was used to generate the design and analyze the outputs of the experiments. The calculated E-value 
magnitude of the tested factor shows its effect or its significance in affecting the response. The positive or negative sign of the E-value is indicative of its positive or negative influence on the responses [56]. All runs were performed in triplicates, and the lipase inhibitory activity was determined [49].

\section{Production, purification and identification of the lipase inhibitor}

To achieve maximum PL inhibitor production, AspsarO was inoculated in potato starch broth containing tryptic soy broth at $37^{\circ} \mathrm{C}$ for 6 days. At the end of fermentation, the biomass was separated from eight liters cultures. The broth was subjected to fractionation using methylene chloride $(3 \times 300 \mathrm{ml})$. Pooled methylene chloride soluble fractions were evaporated under reduced pressure (Büchi R-100 Rotary Evaporator, Germany) to get a brownish residue $(60 \mathrm{mg})$. The remaining aqueous layer was concentrated under vacuum and applied to a DiAION HP-20 column $(5 \times 100 \mathrm{~cm})$ (Supelco Analytical, Germany) and eluted with water, 50, and $100 \%$ methanol. The collected fractions were dried under vacuum to obtain the dried aqueous (260 mg), 50\% (800 mg), and $100 \%$ (1.02 g) methanolic fractions. Dried fractions were dissolved in DMSO, and the lipase inhibitor activity was determined. The fractions showing a lipase inhibitor activity were further analyzed by TLC using methanol and chloroform $(95: 5 \mathrm{v} / \mathrm{v})$ as a mobile phase on Silica gel 60 TLC plates (Merck, Germany) [49].

Using a bio-guided approach, the $100 \%$ methanolic fraction was further purified to isolate the main lipase inhibitor. It was chromatographed using PuriFlash 4100 (Interchim, France) using $25 \mathrm{~g}$ flash cartilage (silica gel 60, $30 \mathrm{um}$ ), and eluted with $\mathrm{CH}_{2} \mathrm{CL}_{2}$ : methanol (9.5:0.5 $\sim 90: 10 \mathrm{v} / \mathrm{v})$. Twenty $\mathrm{ml}$ fractions were collected, and the fractions were monitored using TLC and visualized under UV. Fractions with major spots were collected and evaporated under vacuum to obtain semi-pure fractions $(300 \mathrm{mg})$. They were purified on silica gel columns $(2 \times 20 \mathrm{~cm})$ using $\mathrm{CH}_{2} \mathrm{Cl}_{2}$ : methanol $(9.5: 0.5 \mathrm{v} / \mathrm{v})$ as eluent to get a pure compound $(10 \mathrm{mg}$ off-white powder). The identity of the compound was assessed using ${ }^{1} \mathrm{H}$ and ${ }^{13} \mathrm{C} \mathrm{NMR}$, and the obtained data was compared to literature [22].

\section{Molecular docking study}

The Molecular Operating Environment (MOE, 2015.10) software was used in all molecular modeling studies. All minimizations were done, using MOE, until an RMSD gradient of $0.05 \mathrm{kcal} \cdot \mathrm{mol}^{-1} \AA^{-1}$ was reached using a MMFF94x force field. Partial charges were calculated automatically. The X-ray crystallographic structure of human pancreatic lipase (PDB ID: 1LPB) was downloaded from the protein data bank [57]. We removed the water molecules and ligands not involved in binding from the co-crystallized enzyme. The enzyme was prepared, for docking, using the Protonate $3 D$ protocol in MOE with default settings. The co-crystallized ligand was used to define the binding site. Triangle Matcher placement method and London dG scoring function were used in docking [58].

\section{Determination of $\mathrm{IC}_{50}$}

Dried 100\% methanolic fractions of AspsarO and kojic acid were dissolved in DMSO to get the following concentrations: $1,5,10,25,50$, and $100 \mu \mathrm{g} / \mathrm{ml}$. Similar concentrations of orlistat (reference standard) were also prepared. The PL inhibitor activity of all the prepared concentrations was measured [49]. $\mathrm{IC}_{50}$ was calculated by plotting log (dose)-response inhibition curve using the equation "log (inhibitor) vs. response" with GraphPad Prism software [8].

\section{Evaluating the AspsarO lipase inhibitor in a high fat diet (HFD) induced obesity animal model \\ Animals}

Six weeks old male Sprague-Dawley rats weighing from $125 \mathrm{~g}$ to $165 \mathrm{~g}$ were purchased from New veterinary center (Cairo, Egypt). Rats were kept in the laboratory animal housing at the faculty of Pharmacy, Cairo University, following the recommendations of the guide for care and use of laboratory animals. They were randomly assigned to polycarbonate cages, with bedding of husk, and 12-h light/dark cycles; feed and water were given ad libitum. Environmental conditions were maintained at a temperature of $22^{\circ} \mathrm{C} \pm 2{ }^{\circ} \mathrm{C}$ and relative humidity of $60 \% \pm 10 \%$. All animal procedures were performed as per the international ethical guidelines and the National Institute of Health guide concerning the care and use of laboratory animals.

\section{Acute toxicity testing}

The acute toxicity test of the dried 100\% methanolic fraction of AspsarO was performed as per the organization for European economic cooperation (OECD) guidelines No. 420. Increasing doses of 100, 400,800 , and $1000 \mathrm{mg} / \mathrm{kg}$ of the tested extract in distilled water, were administered as a single dose (one ml) by oral gavage to four rats; one rat received distilled water and served as a control. Pharmacotoxicity signs like changes in the skin, fur, eyes, respiratory and central nervous systems, and any changes in behavior or physical activities were observed at $10 \mathrm{~min}, 30 \mathrm{~min}, 60 \mathrm{~min}$, $120 \mathrm{~min}, 4 \mathrm{~h}$, and $6 \mathrm{~h}$ after treatment. Treated animals were daily monitored during the period of the study for mortality, and any pharmacotoxicity signs [59]. 


\section{Experimental design}

Following 1 week of acclimatization with pelletized commercial diet, we randomly divided the rats into three groups of five rats each. The groups were as follows: group on a normal diet, a HFD-fed group, and a HFDfed group receiving $100 \mathrm{mg} / \mathrm{kg} /$ day of the dried $100 \%$ methanolic fraction of AspsarO dissolved in water. The extract was administered as a single daily oral dose for 28 days. HFD was prepared by mixing $35 \%$ ghee with the ground standard diet. The food intake and body weight were monitored every $48 \mathrm{~h}$ [60].

\section{Biochemical parameters}

Following 4 weeks of treatment, blood samples were collected from $12 \mathrm{~h}$ fasted rats by retro-orbital puncture, and serum was separated by centrifugation at $2000 \times \mathrm{g}$ for $10 \mathrm{~min}$. Serum total cholesterol (TC) and triglycerides (TGs) were determined using commercial kits (Roche, Germany) and Cobas 8000 automated analyzer (Roche, Germany). Rats were sacrificed by cervical dislocation under anesthesia, and the livers were dissected and weighed $[38,59]$.

\section{Statistical analysis}

We used the GraphPad Prism 7 software for statistical analysis, including t-test, One-way ANOVA, and Dunnett's multiple comparisons post-test at a $p$-value $<0.05$. Results were expressed as mean \pm standard deviation (SD) $(n=3)$. Also, unpaired Student's t-test and Oneway ANOVA followed by Sidak's or Holm-Sidak's multiple comparisons tests were used for analyzing the animal model experiments. The results were expressed as mean \pm standard error (SEM) $(n=5)$ and were considered significantly different at a $p$-value $<0.05$ (GraphPad Prism, version 7, GraphPad, La Jolla, CA).

\section{Supplementary information}

Supplementary information accompanies this paper at https://doi.org/10. 1186/s12896-020-00644-9.

Additional file 1: Figure S1. AspsarO colonies morphology on PDA, CYA and MEA where: $(a, c, e)$ are AspsarO front view on PDA, CYA and MEA, respectively; $(b, d, f)$ are AspsarO colonies reverse view on PDA, CYA and MEA, respectively.

Additional file 2: Figure S2. AspsarO microscopical characters where: a) Wet mount showing AspsarO conidia head under Olympus microscope at 40X magnification. Conidia heads are radiate spherical to globose. b) Conidia spores of AspsarO under Olympus microscope at 40X magnification. Conidia spores are round to oval, and arranged in chains.

\section{Abbreviations}

CD: Cafeteria diet; CYA: Czapek yeast extract agar; FDA: Food and drug administration; HFD: High fat diet; KA: Kojic acid; MEA: Malt extract agar MUB: 4-methylumbelliferyl butyrate; PDA: Potato dextrose agar;

PL: Pancreatic lipase; PNPP: $p$-nitrophenyl palmitate; TC : Total cholesterol; TG: Triglycerides; TSB: Tryptic soy broth; WHO: World Health Organization; YE: Yeast extract

\section{Acknowledgments}

We would like to thank Dr. Mohamed Kandeel, PhD for technical support in docking analysis.

\section{Permission to collect sample}

No permission was necessary to collect samples.

\section{Authors' contributions}

SME performed the experiments, collected and interpreted experimental data, and wrote the initial draft of the manuscript. OMH performed morphological and molecular identification of the fungal isolate, phylogenetic analysis, designed and supervised the experiments, contributed to writing and finally revised the final content. AME fractionated, purified, and identified the major compound, and contributed to writing the manuscript. YER supervised the experiments and edited the manuscript. $\mathrm{HHZ}$ conceived this study, reviewed and revised the manuscript. All authors read and approved the final manuscript.

\section{Funding}

This research did not receive any specific grant from funding agencies in the public, commercial, or non-profit sectors.

\section{Availability of data and materials}

The datasets used and/or analyzed during the current study are available from the corresponding author on reasonable request.

\section{Ethics approval and consent to participate}

All animal procedures were performed in accordance with the international ethical guidelines and the National institutes of health guide concerning the care and use of laboratory animals. They were approved by the research ethical committee at the faculty of Pharmacy, Cairo University, with the approval number MI (2059).

\section{Consent for publication}

Not applicable.

\section{Competing interests}

The authors declare that they have no competing interests.

\section{Author details}

${ }^{1}$ Department of Microbiology and Immunology, Faculty of Pharmacy, Cairo University, Cairo, Egypt. ${ }^{2}$ Department of Pharmacognosy, Faculty of Pharmacy, Cairo University, Cairo, Egypt.

Received: 10 June 2020 Accepted: 10 September 2020

Published online: 02 October 2020

\section{References}

1. Grundy S. Multifactorial causation of obesity: implications for prevention. Am J Clin Nutr. 1998;67:563-72.

2. World Health Organisation: Obesity and overweight. Geneva. https://www. who.int/news-room/fact-sheets/detail/obesity-and-overweight (2020). Accessed 1 Aug 2020

3. Khaodhiar L, McCowen K, Blackburn G. Obesity and its comorbid conditions. Clin Cornerstone. 1999:2:17-31.

4. World Health Organisation: The Global Health Observatory (GHO) Data. Geneva. https://www.who.int/data/gho/data/themes/theme-details/GHO/ body-mass-index-(bmi) (2020). Accessed 1 Aug 2020.

5. Kun W, Gang-Qiang W, Xue B, Yan-Fen N, He-Ping C, Chun-Nan W, et al. Structure-based optimization and biological evaluation of pancreatic lipase inhibitors as novel potential antiobesity agents. Nat Products Bioprospect. 2015;5(3):129-57.

6. Ashkan A, Mohammad HF, Marissa BR, Patrick S, Kara E, Alex L. Health effects of overweight and obesity in 195 countries over 25 years. N Engl J Med. 2017;377:13-27.

7. Gupta M, Sanjai S, Dinesh G. Lipase inhibitory activity of endophytic fungal species of Aegle marmelos: a bioresource for potential pancreatic lipase inhibitors. Symbiosis. 2014;64:149-57.

8. Katoch M, Paul A, Singh G, Sridhar SNC. Fungal endophytes associated with Viola odorata Linn. as bioresource for pancreatic lipase inhibitors. BMC COMPLEM ALTERN M. 2017;17:385. 
9. Shamsiya TK, Manjunatha JR, Manonmani HK. Lipase inhibitors from Nigella sativa and Punica granatum as an effective approach towards controlling obesity. Int J Health Life Sci. 2016;2(2):1-19.

10. Filippatos T, Derdemezis C, Gazi I, Nakou E, Mikhailidis D, Elisaf M. Orlistatassociated adverse effects and drug interactions: a critical review. Drug Saf. 2008;31(1):53-65.

11. Birari R, Bhutani K. Pancreatic lipase inhibitors from natural sources: unexplored potential. Drug Discov Today. 2007;12:879-89.

12. Gupta M, Sanjai S, Dinesh G. Potential pancreatic lipase inhibitory activity of an endophytic Penicillium species. J Enzyme Inhib Med Chem. 2015;30(1): $15-21$.

13. Kim GW, Lin JE, Blomain ES, Waldman SA. Anti-obesity pharmacotherapy: new drugs and EmergingTargets. Clin Pharmacol Ther. 2014;95(1):53-66.

14. Samuel $P$, Prince $L$, Prabakaran $P$. Antibacterial activity of marine derived fungi collected from South East Coast of Tamil Nadu. India J Microbiol Biotech Res. 2011;1:86-94.

15. Goldman G, Osmani S. The Aspergilli: genomics, medical aspects, biotechnology, and research methods. 1st ed. Boca Raton: CRC Press; 2008

16. Samson R, Varga J. What is a species in Aspergillus? Med Mycol J. 2009;47: $13-20$.

17. Masayuki M, Katsuya G. Aspergillus: molecular biology and genomics. Biotechnol J. 2010;5:336-7.

18. Bentley R. From miso, sake and shoyu to cosmetics: a century of science for kojic acid. Nat Prod Rep. 2006;23:1046-62.

19. Hazzaa MM, Saad AM, Hassan HM, Ibrahim El. High production of Kojic acid crystals by isolated Aspergillus oryzae var. effusus NRC14. J. Appl Sci Res. 2013;9(3):1714-23.

20. Saeedia M, Masoumeh E, Khadijeh K. Kojic acid applications in cosmetic and pharmaceutical preparations. Biomed Pharmacother. 2019;110:582-93.

21. Abdel-Halim O. A new tyrosinase inhibitor from Crinum yemense as potential treatment for hyperpigmentation, die Pharmazie-an. Int J Pharm Sci Res. 2008;63(5):405-7.

22. Antonius RBO, Gema M, Caterina SL, Yoseph S, Philipi DR, Dodi D, et al. Single Production of Kojic Acid by Aspergillus flavus and the Revision of Flufuran. Molecules. 2019;24(4200).

23. Ruilin Z, Jian C, Xinwu M, Ping Q, Xuewu Z. Separation and lipid inhibition effects of a novel Decapeptide from Chlorella pyenoidose. Molecules. 2019; 24:3527-43.

24. Prashith K, Shobha K, Onkarappa R. Pancreatic lipase inhibitory and cytotoxic potential of a Streptomyces species isolated from Western Ghat soil, Agumbe, Karnataka. India Int J Pharm Biol Arch. 2011;2(3):932-7.

25. Tokdar P, Ranadive P, Mascarenhas M, Patil S, George S. (E)-4-aminostyryl acetate a novel pancreatic lipase inhibitor produced by a Streptomyces sp. MTCC 5219. Int J Chem Eng Appl. 2011:2:135-8.

26. Nyongesa BW, Okoth S, Ayugi V. Identification key for Aspergillus species isolated from maize and soil of Nandi County. Kenya Adv Microbiol. 2015;5: 205-29.

27. Devi KBD, Vijayalakshmi P, Shilpa V, Kumar BV. Screening of anti-cancerous compound kojic acid by a novel fungal isolates from economically inexpensive nutritive sources. Int J Innov Res Tech Sci. 2016;4(1):41-7.

28. Liu D, Wang F, Liao T. Vibralactone: a lipase inhibitor with an unusual fused beta-lactone produced by cultures of the basidiomycete Boreostereum vibrans. Org Lett. 2006;8:5749-52.

29. Teymouri M, Maryam K, Farhad G, Javad A. Marzban. A. Extracellular lipase purification from a marine Planomicrobium sp. MR23K and productivity optimization in a pilot-scale submerged bioreactor. Proc Natl Acad Sci. 2016;88(2):739-46.

30. Hassan HM, Saad AM, Hazzaa MM, Ibrahim El. Optimization study for the production of Kojic acid crystals by Aspergillus oryzae var. effusus NRC 14 isolate. Int J Curr Microbiol Appl Sci. 2014;3(10):133-42.

31. Chang S-W, Shaw J-F, Yang K-H, Chang S-F, Shieh C-J. Studies of optimum conditions for covalent immobilization of Candida rugosa lipase on poly (cglutamic acid) by RSM. Bioresour Technol. 2008;99(8):2800-5.

32. Azzahra AF, Sukarna DKP, Suryadi H. Optimization Of Aspergillus Oryzae Fermentation Conditions For Kojic Acid Production. Int J App Pharm. 2018;10:1.

33. Rosfarizan M, Mohd SM, Nurashikin S, Madihah MS, Arbakariya BA. Kojic acid: applications and development of fermentation process for production. Biotechnol Mol Biol Rev. 2010;5(2):24-37.

34. Rosfarizan M, Madihah S, Ariff AB. Isolation of a kojic acid-producing fungus capable of using starch as a carbon source. Lett Appl Microbiol. 1998;26:27-30.
35. Suwarjo ID, Azzahra AF, Suryadi H. Isolation of Kojic acid producing Mold using complex carbon sources. Pharmacogn J. 2018;10(6):1089-92.

36. Gad A. Modification of molasses for kojic acid production by Aspergillus parasiticus. N Egypt J Microbiol. 2003;5:14-26.

37. Promsang A, Rungsardthong V, Thumthanaruk B, Puttanlek C, Uttapap D, Foophow T, et al. Effect of culture conditions and medium compositions on kojic acid production by Aspergillus oryzae ATCC 10124. Environ Earth Sci. 2019;346.

38. Kumar S, Alagawadi KR. Anti-obesity effects of galangin, a pancreatic lipase inhibitor in cafeteria diet fed female rats. Pharm Biol. 2013;51(5):607-13.

39. Kishino E, Ito T, Fujita K, Kiuchi Y. A mixture of the Salacia reticulata (Kotala himbutu) aqueous extract and Cyclodextrin reduces the accumulation of visceral fat mass in mice and rats with high-fat diet-induced obesity. Nutr J. 2006;136:433-9.

40. Festi D, Colecchia A, Sacco T. al. e. Hepatic steatosis in obese patients: clinical aspects and prognostic significance. Obes Rev. 2004;5:27-42

41. Zhao H, Sim J-S, Shim S, Ha Y, Kang S, Kim Y. Antiobese and hypolipidemic effects of platycodin saponins in diet-induced obese rats: evidences for lipase inhibition and calorie intake restriction. Int J Obes. 2005;29:983-90.

42. Miyake Y, Mochizuki M, Ito C, Itoigawa M, Osawa T. Antioxidative pyranonigrins in rice mold starters and their suppressive effect on the expression of blood adhesion molecules. BIOSCI BIOTECH BIOCH. 2008;72: 1580-5.

43. Choi H, Kim K, Han J, Jin S, Lee E, Shin D, et al. Kojic acidinduced IL-6 production in human keratinocytes plays a role in its anti-melanogenic activity in skin. J Dermatol Sci. 2012;66:207-15.

44. Yoshizaki Y, Chihiro K, Kai-Chun C, Miharu U, Haruka A, Akihiro A, et al. Rice koji reduced body weight gain, fat accumulation, and blood glucose level in high-fat diet-induced obese mice. PeerJ. 2014;540:1-17.

45. Shin HW, Jang ES, Moon BS, Lee JJ, Lee DE, Lee CH, et al. Anti-obesity effects of gochujang products prepared using rice koji and soybean meju in rats. J Food Sci Technol. 2016:53(2):1004-13.

46. Hee-Kyoung S, Hye-Won S, Eun-Seok J, Byoung-Seok M, Choong-Hwan L, Jae-Joon L. Comparison of Antiobesity effects between Gochujangs produced using different Koji products and Tabasco hot sauce in rats fed a high-fat diet. J Med Food 2018:00(0):1-11.

47. Naveen BK. Production of novel lipase inhibitor from Streptomyces sp. India: University of Mysore; 2005.

48. Kordel M, Schmid RD. Inhibition of the lipase from Pseudomonas sp. ATCC 21808 by diethyl $p$-nitrophenyl phosphate. In: Alberghina L, Verger R, Schmid Weinheim RD, editors. hints for one buried active site for lipolytic and esterolytic activity. Germany: VCH; 1991. p. 385-8.

49. Tk S. Nanishankar V, Harohally., Manonmani HK. Production and purification of a new inhibitor of pancreatic lipase andHormone sensitive lipase from soil Actinomycetes. Int J innovative research in science, engineering and. Technology. 2015;4(11):11600-9.

50. Klich MA. Identification of common Aspergillus species. Utrecht: Centraalbureau voor Schimmelcultures; 2002.

51. Osmundson TW, Catherine AE, Katherine MH, Jaskirn D, Matteo MG. Back to basics: an evaluation of $\mathrm{NaOH}$ and alternative rapid DNA extraction protocols for DNA barcoding, genotyping, and disease diagnostics from fungal and oomycete samples. Mol Ecol Resour. 2013;13:66-74.

52. Medlin L, Elwood H, Stickel S, Sogin M. The characterization of enzymatically amplified eukaryotic 16S-like rRNA-coding regions. Genetica. 1988;71:491-9.

53. National Centre for Biotechnology Information. http://blast.ncbi.n/m.nih.gov/ Blast.cgi. Accessed 27 Sept 2018.

54. Kumar S, Stecher G, Li M, Knyaz C, Tamura K. MEGA X: Molecular evolutionary genetics analysis across computing platforms. Mol Biol Evol. 2018;35:1547-9.

55. Korayem AS, Abdelhafez AA, Zaki MM, Saleh EA. Optimization of biosurfactant production by Streptomyces isolated from Egyptian arid soil using Plackett-Burman design. Ann Agric Sci. 2015;60(2):209-17.

56. Hashem RA, Samir R, Essam TM, Ali AE, Amin MA. Optimization and enhancement of textile reactive Remazol black $B$ decolorization and detoxification by environmentally isolated $\mathrm{pH}$ tolerant Pseudomonas aeruginosa KY284155. AMB Express. 2018;8:83-95.

57. Berman $H$, Westbrook J, Feng Z, Gilliland G, Bhat $T$, Weissig $H$, et al. The protein data bank. Nucleic Acids Res. 2000;28:235-42.

58. Hoai-Anh N, Trong-Nhat D, Van-Dat T, Khac-Minh T, Ngoc-Chau T, ThanhDao T. Design, synthesis and biological evaluation of some Chalcone derivatives as potential pancreatic lipase inhibitors. The 17th international electronic conference on synthetic organic chemistry. Vietnam: MDPI; 2013. 
59. Rajasekaran A, Arivukkarasu R. Acute and sub-acute toxicity study of aqueous extracts of Canscora heteroclita (L) Gilg in rodents. Pharmacogn I. 2016;8(4):399-410.

60. R-RI F, Gerardo NE-C, Leticia G-S, G-Ha C, Norma PC. Antiobesity and

Hypoglycaemic Effects of Aqueous Extract of Ibervillea sonorae in Mice Fed a High-Fat Diet with Fructose. J BIOMED BIOTECHNOL. 2011;2011:1-6.

\section{Publisher's Note}

Springer Nature remains neutral with regard to jurisdictional claims in published maps and institutional affiliations.

Ready to submit your research? Choose BMC and benefit from:

- fast, convenient online submission

- thorough peer review by experienced researchers in your field

- rapid publication on acceptance

- support for research data, including large and complex data types

- gold Open Access which fosters wider collaboration and increased citations

- maximum visibility for your research: over $100 \mathrm{M}$ website views per year

At BMC, research is always in progress.

Learn more biomedcentral.com/submissions 